\title{
A política numa política do Trabalho Escravo: alguns apontamentos sobre o Compromisso Nacional da Cana de Açúcar.
}

Gabriel da Silva Teixeira ${ }^{1}$

O agronegócio sucroenergético brasileiro oferece um ambiente bastante rico para se refletir sobre o exercício das políticas participativas. Em 2008, empresários do setor, governo e representantes dos trabalhadores canavieiros se reuniram para contornar os frequentes conflitos trabalhistas da atividade. A Mesa Nacional de Diálogo, nome dado ao espaço de discussão, durou um ano, celebrando em 2009 um conjunto de normas que passariam a orientar a prática patronal na contratação e utilização de trabalhadores para o corte manual. O conjunto das normas foi chamado de Compromisso Nacional da Cana de Açúcar e dentre seus principais pontos estão as práticas formalizadas e diretas de contratação de trabalhadores (sem mediadores), atendimentos relativos à saúde do trabalhador (como o oferecimento de equipamentos de proteção, pausas periódicas na atividade de corte manual para descansos, ambientes higiênicos para necessidades durante a atividade de corte e a segurança no translado dos trabalhadores, acompanhamento médico periódico, etc.) e também a permissão da atuação sindical dentro das empresas, desde que comunicadas antecipadamente. Tais pontos não foram deliberados sem controvérsias e embates, como tentaremos mostrar ao longo do trabalho. Ao todo foram necessárias 18 reuniões para o encaminhamento dos acordos (Lambertucci, 2010). O pacto tripartite também comprometia os empresários signatários a um processo posterior de fiscalização, através de auditagens privadas feitas por quatro

\footnotetext{
${ }^{1}$ Doutorando do Programa de Pós-Graduação em Ciências Sociais da Universidade Estadual de Campinas (Unicamp) e Mestre em Ciências Sociais em Desenvolvimento, Agricultura e Sociedade pelo CPDA/UFRRJ.
}

Brasiliana - Journal for Brazilian Studies. Vol. 2, n.2 (Nov 2013). ISSN 2245-4373. 
empresas de auditoria ${ }^{2}$, visando observar o cumprimento dos pontos pactuados. Todos os critérios da auditagem foram elaborados pela própria comissão tripartite. $\mathrm{O}$ cumprimento empresarial dos pontos acordados implicaria na concessão de um selo de conformidade por parte do governo federal, forma de atestar a "qualidade" social e trabalhista das empresas, num momento de euforia em relação ao comércio mundial de etanol e outros bicombustíveis. Nas discussões da Mesa de Diálogo estiveram presentes a Federação de Empregados Rurais Assalariados do Estado de São Paulo (FERAESP), a Confederação Nacional dos Trabalhadores da Agricultura (CONTAG), a União das Indústrias da Cana de Açúcar (ÚNICA) e o Fórum Nacional Sucroalcooleiro (FNS). O governo se envolve a partir de distintos ministérios. Na ossatura estatal, o Compromisso Nacional se ancora à Secretaria Geral da Presidência da República (SGPR), criada pelo governo Lula, sob a responsabilidade de antigos dirigentes sindicais "cutistas" com o objetivo de mediar a relação da presidência junto à sociedade civil em sua diversidade.

Uma primeira constatação é que o espaço que se propunha deliberativo, em sua realidade, não o foi. O conjunto de atores políticos aglutinados na Mesa de Diálogo, principalmente os representantes dos trabalhadores, alteravam pouco o curso de decisões já tomadas em outros espaços. Grande parte dos pontos do Compromisso Nacional já tinha sido acordada anteriormente pelo Conselho de Desenvolvimento Econômico e Social (CDES), antes mesmos de ser apresentada aos representantes na Mesa de Diálogo (Teixeira, 2013). Outro aspecto diz respeito à amplitude da Mesa. A discussão sobre os pontos que comporiam o Compromisso Nacional não levou em conta a diversidade de sujeitos envolvidos com a temática do trabalho escravo na cana, como pretendemos mostrar ao longo do trabalho.

2 KPMG, Delloitt Touche, Ernst e Young e Uhy Moreira Auditoria. As quatro empresas foram licitadas a partir de um anúncio público.

Brasiliana - Journal for Brazilian Studies. Vol. 2, n.2 (Nov 2013). ISSN 2245-4373. 
A Mesa de Diálogo foi objeto de polêmica e críticas variadas de diversos atores. O Compromisso Nacional foi questionado publicamente como uma manobra de "cooptação" dos trabalhadores por parte do executivo e empresários e/ou de "peleguisse" das representações sindicais³ ${ }^{3}$ Fizemos o esforço de situar tais análises dentro do próprio campo político de disputas sobre a discussão. Vista mais de perto, a arena permite-nos identificar embates e conflitos políticos que nos auxiliam a compreender os diferentes atores do setor sucroalcooleiro e seus projetos políticos na atualidade.

\section{Participação Institucional e o Compromisso Nacional da Cana de Açúcar}

Diversos esforços têm sido empreendidos na tentativa de entender os espaços de participação como espaços de disputa, ainda que limitados por diversos fatores. Passando ao largo de uma análise mais simplificadora, que atribua à incorporação de setores subalternos em arenas institucionais a insígnia da "democratização", sem problematizá-la, nosso esforço reside na tentativa de perceber a persistência de conflitos no interior deste espaço de forma a qualificar a processo de participação social no caso do agronegócio canavieiro recente. Diferentemente do "registro celebratório e otimista" que salientava o aspecto democratizante da participação social nas instâncias estatais (registro mais adequado à abertura democrática dos anos 1980), a literatura recente sobre participação social nos leva a enfatizar a "qualidade" do processo participativo (Dagnino e Tatagiba, 2010).

3A este respeito, por exemplo, ver Maurício Reimberg. Governo prepara protocolo; Alimentação é cara, dizem os usineiros. Repórter Brasil, São Paulo, 02 jun. 2009. Disponível em:

<http://www.reporterbrasil.org.br/exibe.php?id=1589>. Acesso em ago. 2012.

Brasiliana - Journal for Brazilian Studies. Vol. 2, n.2 (Nov 2013). ISSN 2245-4373. 
Teixeira, Gabriel da Silva. A Política numa Política do Trabalho Escravo: Alguns Apontamentos sobre o Compromisso Nacional da Cana de Açúcar.

A recusa ao "registro celebratório" reside na constatação de que enquanto expressão e continuidade de disputas sociais, os espaços participativos, antes de garantirem, necessariamente, maior aprofundamento da democratização, trazem para dentro de si as assimetrias e os diversos conflitos existentes em sociedade. O desafio presente na análise de casos como o Compromisso Nacional reside em apreender os sentidos atribuídos à participação por cada participante e perseguir as controvérsias, as pautas consideradas "polêmicas", as regras "imobilizadoras", identificando eventuais limites na capacidade de influência de setores sociais subalternos em contextos de políticas "democráticas". Sem desconsiderar a "política" por detrás das críticas atribuídas ao Compromisso Nacional, tratar da institucionalização de temáticas e/ou grupos sociais específicos através de noções como "cooptação/peleguisse", como se pressupusessem relações de um só tipo diante de uma diversidade de atores e estratégias de enfrentamento político (Dagnino e Tatagiba, 2010), desconsidera a própria disputa entre os setores participantes como também a ampla mobilização da sociedade civil em prol das melhorias trabalhistas na atividade ${ }^{4}$, mobilização que certamente contribuiu para a formação do espaço em questão.

Avaliando a modificação dos repertórios de atuação dos movimentos sociais a partir da institucionalização de alguns de seus quadros políticos, Evelina Dagnino e Luciana Tatagiba (2010) questionam a manutenção de conceitos e referenciais utilizados

\footnotetext{
${ }^{4}$ ONGs, setores do judiciário e da igreja católica, por exemplo, tomaram a frente na denúncia dos maus tratos aos trabalhadores rurais. Dentre as ONGs, vemos grande protagonismo da Repórter Brasil; dentre os movimentos sociais temos a Comissão Pastoral da Terra e o Grupo de Pesquisas sobre Trabalho Escravo (GPTEC); além dos diversos membros da Secretaria de Inspeção do Trabalho, vinculada ao Ministério do Trabalho e Emprego, bem como setores do Ministério Público do Trabalho. O Ministério do Desenvolvimento Agrário (MDA) também se envolveu com os conflitos trabalhistas, promovendo programas de desenvolvimento regional em localidades afetadas pelos conflitos. O Conselho Nacional pela Erradicação do trabalho Escravo (CONATRAE) também teve forte influência na ampliação da temática. Por parte da representação sindical, percebe-se, em maior ou menor grau, a organização de greves por parte da Feraesp e por parte da Fetaesp, vinculada à Confederação de Trabalhadores da Agricultura (Contag).
}

Brasiliana - Journal for Brazilian Studies. Vol. 2, n.2 (Nov 2013). ISSN 2245-4373. 
em outros momentos históricos para se pensar a disputa política na atualidade. A institucionalização de movimentos sociais pode não só representar etapas importantes da luta política - através da capacidade orgânica de interferir em políticas públicas e em decisões estatais que considerem os desejos e reivindicações de seus membros - como tem se tornado, na atualidade, um importante recurso de vários movimentos sociais na busca pelo atendimento de suas reivindicações. Ao desconsiderar a possibilidade da participação social significar avanço na capacidade de pressão e mobilização de grupos sociais, as interpretações mais simplistas comumente esgotam a complexidade de casos concretos de institucionalização. Entender tais processos numa perspectiva mais relacional permitiria visualizar a participação institucional também como disputa, ampliando a ótica pessimista da "cooptação", contribuindo inclusive, na reorientação das questões de análise, perscrutando elementos mais significativos que explicitem as disputas e os conflitos políticos inerentes à arenas participativas.

Ao mostrar que os Estados modernos são mais complexos que as formações nacionais pré-modernas e que a diversidade de formas de experimentação da vida propiciada pela complexidade das sociedades desloca a luta política para uma luta pela "direção intelectual e moral" do conjunto dos atores sociais, Gramsci (1976) ressalta o papel da "luta por posição". Para o autor, separar a sociedade civil (inclusive os segmentos conservadores), da sociedade política (inclusive os segmentos progressistas) retira da análise a complexidade inerente à disputa política nas sociedades modernas.

Nas análises dicotomizantes acaba por ficar de fora a diversidade de "vinculações, articulações e trânsitos entre ambas as esferas de atividade [Estado e sociedade civil], onde a disputa entre distintos projetos políticos estrutura e dá sentido a luta política" (Dagnino, Olvera e Panfichi, 2006). Para os autores, perdemos de vista a possibilidade de a participação social ser um avanço político de setores sociais subalternos, que passam a ser considerados em arenas até então exclusivas de certos 
grupos sociais. Caberia determinar, portanto, em que medida, tal política participativa implicaria em avanço efetivo da participação de segmentos até então alijados dos espaços de decisão, ou se simplesmente reafirmariam - sob nova roupagem - grupos e processos sociais conservadores (Offe, 1989). Caberia indagarmos em que medida o pacto representa a imposição de melhorias nas condições trabalho para os segmentos patronais ou, em que medida, guardou em si os impulsos conservadores de outros atores porventura participantes. Cabe destacar que é sempre mais provável que percebamos as duas posições nos espaços participativos, em que a inclusão de setores antes alijados da decisão vem acompanhada de relações personalistas, clientelistas, excludentes, etc.

Entendendo os espaços institucionais como espaços de disputa política é que as próximas sessões pretendem debater os embates e conflitos existentes dentro deste arranjo participativo. Esperamos, com este exercício, ampliar o entendimento acerca dos "pontos polêmicos", dos distintos atores políticos, dos seus projetos e eventuais deslocamentos na rede de poder dentro do agronegócio sucroalcooleiro na atualidade.

\section{Atores e Projetos Políticos para o Trabalho e Trabalhadores na Cana: O Que Nos Dizem as Disputas no Compromisso Nacional?}

A própria história do sindicalismo rural paulista nos possibilita questionar interpretações que tendem a enxergar na institucionalização algo necessariamente perverso. Não fosse assim, estranharíamos a constatação de que diversas lideranças sindicais canavieiras ocuparam e continuam ocupando cargos como os de prefeitos e vereadores em alguns municípios do interior de São Paulo (Teixeira, 2013). Tal fato nos mostra que o Estado, antes de ser uma entidade homogênea, é uma arena aberta e 
permeável aos diversos impulsos sociais, expressando as correlações de força entre os diversos grupos e seus respectivos projetos (Gramsci, 1976). Nesse registro mais relacional caberia, portanto, atentar para as mobilizações dos diferentes grupos que movimentaram o cenário dos canaviais brasileiros à época do Compromisso Nacional, desde os mais conservadores, até os mais engajados na ampliação da participação social. Diversas organizações foram responsáveis pela sua constituição, ainda que indiretamente, através de denúncias, manifestações públicas nacionais e/ou internacionais, da fiscalização das condições de trabalho nos canaviais, etc., tornando os conflitos trabalhistas uma problemática pública e carente de resolução. Cabe a nós, todavia, indagarmos em que medida tais atores foram incorporados (ou não) ao jogo político deliberativo ou, em que medida tiveram suas demandas atendidas pelo mesmo.

Por parte do governo é preciso considerar os diferentes grupos que o compõe. De um lado, este se fez presente, principalmente, pelos segmentos patronais ${ }^{5}$ e por antigos segmentos sindicais cutistas. Do lado dos representantes cutistas, como já citado, temos a Secretaria Geral da Presidência da República (SGPR), que articulou e conduziu o Compromisso $\mathrm{Nacional}^{6}$, disposta a cumprir uma agenda progressista, fortemente referenciada na noção de "desenvolvimento com equidade" (CUT, 2000). Para tal concepção, o desenvolvimento a ser perseguido pelo governo implicaria na conciliação da expansão da atividade sucroenergética com a resolução dos conflitos trabalhistas notados. Tal fato se traduziu num amplo fomento à expansão sucroenergética (Tabela 1) e num condicionamento de tal expansão à resolução dos diversos conflitos que despontavam nos canaviais brasileiros.

\footnotetext{
${ }^{5}$ Expressivo foi o caso do Ministro da Agricultura do governo Lula em 2003 - Roberto Rodrigues - um expoente produtor rural, dono de empresa de consultoria agrícola, fornecedor de cana-de-açúcar e sócio de algumas usinas no país.

${ }^{6}$ Cabe ressaltar que os principais nomes envolvidos na articulação do Compromisso Nacional eram antigos dirigentes sindicais urbanos, em especial metalúrgicos.
}

Brasiliana - Journal for Brazilian Studies. Vol. 2, n.2 (Nov 2013). ISSN 2245-4373. 
Teixeira, Gabriel da Silva. A Política numa Política do Trabalho Escravo: Alguns Apontamentos sobre o Compromisso Nacional da Cana de Açúcar.

Tabela 1 - Desembolsos do BNDES por atividade produtiva para o setor sucroalcooleiro no período 2004-2010* (em RS milhões)

\begin{tabular}{lccccccc}
\hline Atividade Produtiva & $\mathbf{2 0 0 4}$ & $\mathbf{2 0 0 5}$ & $\mathbf{2 0 0 6}$ & $\mathbf{2 0 0 7}$ & $\mathbf{2 0 0 8}$ & $\mathbf{2 0 0 9}$ & $\mathbf{2 0 1 0}$ \\
\hline Cana-de-Açúcar & 193 & 224 & 366 & 571 & 686 & 688 & 953 \\
Industrial (Açúcar e Etanol) & 333 & 617 & 1.344 & 2.893 & 3.942 & 4.184 & 5.139 \\
Cogeração & 77 & 256 & 264 & 127 & 1.872 & 1.522 & 1.483 \\
\hline Total & $\mathbf{6 0 3}$ & $\mathbf{1 . 0 9 7}$ & $\mathbf{1 . 9 7 4}$ & $\mathbf{3 . 5 9 1}$ & $\mathbf{6 . 5 0 0}$ & $\mathbf{6 . 3 9 4}$ & $\mathbf{7 . 5 7 5}$ \\
\hline $\begin{array}{l}\text { Fonte: BNDES } \\
\text { *Inclui todas as linhas de crédito do Banco (operações diretas e indiretas, automáticas e não-automáticas). }\end{array}$
\end{tabular}

Arthur Henrique, então presidente da Central Única dos Trabalhadores (CUT), descreve os sentidos do Compromisso Nacional, na visão da entidade:

"Numa das reuniões do CDES, o então presidente Lula falava sobre a importância do etanol brasileiro diante das mudanças climáticas e da necessidade de utilizar um combustível que emitisse menos gases de efeito estufa. Foi seguido pelos empresários do setor, que defendiam que a utilização da cana-de-açúcar, diferentemente do etanol de milho produzido nos Estados Unidos, não competia com a produção de alimentos. O então presidente da União da Indústria de Cana-de-Açúcar (Unica), também conselheiro do CDES [...] reclamava que na disputa internacional pelo mercado de venda de etanol, ele não conseguia compreender por que as entidades do movimento social e sindical faziam propaganda contra o produto brasileiro[...]. Expliquei a ele as razões do nosso posicionamento: a primeira, a produção brasileira continuava sendo feito com base no trabalho escravo, nos acidentes e mortes por estafa durante o corte de cana; e a segunda, que o avanço da cana-de-açúcar 
para etanol, estava sendo feito em terras que antes eram utilizadas para produção de alimentos. Portanto não se tratava de fazer propaganda contra, mas sim uma constatação da realidade vivida pelos trabalhadores e trabalhadoras do setor" (Henrique, 2013: 317, grifos meus).

A disputa, travada no âmbito da institucionalidade, pautada por um governo que se propunha a conciliar projetos de trabalhadores e do patronato, passa a requerer a convergência entre as proposições governamentais e a capacidade de mobilização e pressão das organizações dos trabalhadores.

"Alguns sindicalistas acreditaram que o governo Lula promoveria mudanças automaticamente, não levando em consideração a correlação de forças, a existência de um Congresso Nacional amplamente conservador, o papel da mídia e do Poder Judiciário, as alianças feitas para chegar à vitória. Essa visão, além de equivocada, poderia levar a acomodação. Afinal de contas, a luta de classes não acabou com a vitória de Lula. No âmbito do governo, alguns integrantes, inclusive com origem no movimento sindical, chegavam a sugerir que o movimento deveria ser mais "moderado" nas cobranças e reivindicações, em nome de garantir a governabilidade e preservar o projeto. Outra visão equivocada, já que para avançar nas mudanças estruturais é necessário pressão e mobilização para disputar as propostas, ainda mais numa correlação de forças desfavorável" (Henrique, 2013: 317). 
A elaboração do Compromisso Nacional, para a CUT, figurava como a oportunidade de resolver os conflitos trabalhistas e melhorar as condições de trabalho na atividade, pautando-se na capacidade de mobilização de suas bases sociais e na correlação de força entre os distintos atores em jogo. A própria condução institucional da SGPR, tendo à frente antigos quadros sindicais cutistas, demonstra a disposição dessa ala do governo em levar ao debate público um determinado projeto de desenvolvimento do setor sucroalcooleiro. No cabo de guerra institucional, a CUT apostava na conciliação de interesses como forma de resolver os casos de descumprimento da legislação trabalhista. Membros da Presidência também afirmaram, reiteradamente, o caráter "não conflitivo" e "cooperativo" desta nova esfera participativa:

"Lula, que se autodefiniu como 'garoto propaganda' do etanol no mundo, disse que décadas atrás, os trabalhadores e os donos das usinas eram 'inimigos de classe, sem sequer se conhecer'. Segundo ele, nos últimos anos, começou a haver uma aproximação entre sindicalistas, o PT e os usineiros e deu como exemplo o mandato do atual deputado Antonio Palocci como prefeito de Ribeirão Preto (SP), que ajudou nesse diálogo" (Trabalhadores..., 2009).'

"Para Lula, [o Compromisso] é um grande avanço. 'Há quarenta anos, isso seria impensável, pois os trabalhadores e empresários não se viam como atores da relação capital e trabalho, mas como inimigos'" (Presidente..., 2009). 
Ganha destaque, nas manifestações, o caráter não conflitivo atribuído ao Compromisso e à cooperação dos diversos segmentos sociais na resolução dos conflitos trabalhistas na cana-de-açúcar.

Outro conjunto de atores sociais também contribuiu na denúncia e visibilidade dos conflitos no interior dos canaviais brasileiros. Pastorais rurais, ONGs, movimentos sociais e segmentos do judiciário, diferentemente da concepção de "desenvolvimento com equidade" difundida pelo governo federal, partilhavam da convicção de que à expansão da matriz sucroenergética brasileira devia-se sobrepor a preocupação em relação à manutenção (se não ampliação expansão em termos equivalentes) dos conflitos sociais em geral e trabalhistas em específico ${ }^{7}$. Mesmo contribuindo para a emergência de uma critica especializada sobre as relações de trabalho no setor sucroalcooleiro, tais organizações ficaram de fora do espaço inaugurado. A constituição do Compromisso Nacional alijou do debate e da deliberação um conjunto significativo dos grupos sociais supracitados.

Institucionalizadas sob a forma de um grupo de trabalho (GT) dentro do CDES, em 2007, as discussões sobre os conflitos canavieiros foram desenvolvidas, inicialmente, contando apenas com a participação do então presidente da CUT, Artur Henrique, e com o empresariado representado pela ÚNICA. As discussões iniciais dentro do GT - e que acabaram por definir, em grande medida, os participantes, pontos a serem debatidos, metas das discussões, etc. - também não contaram com a participação da

\footnotetext{
${ }^{7}$ Para termos dimensão da crítica social que se fazia à natureza dos conflitos trabalhistas no setor, um dos principais importadores do etanol brasileiro, a União Europeia, motivado pelas críticas elaboradas e difundidas internacionalmente não só pela CUT, mas principalmente por diversas organizações brasileiras, passa a cobrar algum tipo de certificação da produção nacional que garanta a "sustentabilidade" do produto, sob pena de embargar a compra.

Disponível em www.cptcursospresenciais.com.br/noticias/agricultura/agroenergia/brasil-propora-selo-para-o-etanol. Acesso em novembro de 2012.
}

Brasiliana - Journal for Brazilian Studies. Vol. 2, n.2 (Nov 2013). ISSN 2245-4373. 
CONTAG nem do FNS. Nos documentos oficiais analisados, ao GT e aos seus subgrupos era atribuída a tarefa de:

"[...] 1) propor recomendações para viabilização dos investimentos públicos e privados na cadeia de produção [sic]; 2) levantar e analisar problemas e distorções em todas as etapas da produção e impactos em relação ao meio ambiente, relações de trabalho, áreas de plantio; 3) avaliar a necessidade de regulação governamental no setor, [...] e 4) analisar e propor medidas para o fortalecimento do papel das cooperativas, do cooperativismo e da agricultura familiar na produção de bioenergia, bem como propostas que garantam o acesso ao crédito pelo produtor familiar." (Secretaria Especial do Conselho de Desenvolvimento Econômico e Social, 2007).

Noutro documento, apontam-se as sugestões do GT, após um ano de discussão, à Presidência:

"Subgrupo Relações de Trabalho. As discussões do GT convergiram para dois aspectos: 1) aperfeiçoar e humanizar as atuais relações de trabalho $e$ mitigar os efeitos da mecanização; e 2) adoção de tecnologias alternativas que preservem os níveis de eficiência produtiva, sem causar desemprego massivo e danos ambientais. Subgrupo Certificação ou Boas Práticas. Os processos de certificação socioambiental são uma tendência mundial em muitos setores e servem para melhorar a imagem dos produtos, facilitar a decisão de compra para clientes e consumidores e 
evitar barreiras ao comércio internacional. O ponto de partida para a discussão de um sistema de certificação deve, obrigatoriamente, abranger os três pilares da sustentabilidade: ambiental, social e econômico [...]." (Secretaria Especial do Conselho de Desenvolvimento Econômico e Social, 2008, grifos do autor, GST).

O projeto governamental de "desenvolvimento com equidade" retirava do debate a noção de conflito e enfatizava o caráter de cooperação, além de condicionar a expansão do setor sucroalcooleiro à "humanização das relações de trabalho", acabando por definir que tal "humanização" seria aferida e atestada através de certificação das agroindústrias nacionais. Como vimos, tal momento pode ser interpretado como um enquadramento do governo frente ao patronato, para que contorne as práticas trabalhistas ainda vigentes. Tal momento, no entanto esteve restrito às lideranças cutistas e à UNICA. Outros atores ficaram de fora do espaço, dentre eles a CONTAG,, FERAESP e FNS, que só entrariam posteriormente na constituição dos diálogos, quando a maioria das pautas já estivesse pronta.

Discutindo a representação política, Luis Felipe Miguel chama de "realismo" o reconhecimento de que o embate político não se resolve em termos de justiça, mas em termos de poder (miguel, 2010: 27). O autor entende que o poder é um recurso fundamental que possibilita a garantia da realização de qualquer objetivo político. Para o exercício do poder em uma arena institucional, consequentemente, um dos requisitos mínimos é o de estar representado no espaço de deliberação. E na definição da agenda a ser debatida/implementada, chama atenção a restrição à participação de outros atores sociais. Em entrevista, alguns políticos próximos à FERAESP afirmaram que a entidade sabia que a pauta tinha sido negociada anteriormente, apontando tal fato como uma limitação da disputa institucional. A determinação da agenda política do pacto nacional 
restrita a certos atores e o comprometimento com a plataforma político-econômica do governo parecem ser elementos significativos que qualificam a "participação social" levada à cabo pelo Compromisso Nacional.

O GT do CDES definiu não só o caráter e o formato da Mesa, mas também retirou dos participantes futuros a possibilidade de opinar sobre temas relacionados à "economia" da expansão sucroenergética. A influência das organizações dos trabalhadores rurais tanto nas "questões econômicas", como na definição de critérios mais justos na compra institucional de etanol foi nula, como nos afirma Élio Neves, dirigente da FERAESP.

"Nós estamos [tentando] a partir daquela mesa, dialogar com a Petrobras, com o BNDES, com a Caixa Econômica Federal, com o Banco do Brasil. Porque é assim. Essas instituições estatais na verdade são as grandes transmissoras de recursos públicos para o setor privado [...]. Na última reunião eu virei pro Ministro e disse o seguinte: 'ministro, eu quero saber quando que a Petrobras vem pra mesa?'. Porque a Petrobras é a maior empregadora do setor. 'Não, não é', ele respondeu. Claro que é, quem é que compra mais álcool? Então quero discutir com a Petrobras. Porque se a Petrobras exigir contrapartida social nos seus contratos nós resolvemos um problemão." (Milano e Pera, 2009).

O relato é emblemático não só dos embates sobre quais seriam as melhores formas de intervir nos canaviais brasileiros, mas também das assimetrias de poder de decisão presentes nestes espaços, dentre os quais a definição dos participantes joga um importante papel. Outras pautas trazidas pela FERAESP e CONTAG também não foram 
consideradas, seja por uma não concordância do patronato, seja por uma impossibilidade de sustentá-las politicamente.

Representantes dos trabalhadores e de alguns segmentos do governo federal apontaram diversos dilemas na dinâmica produtiva da cana-de-açúcar que mereceriam atenção, dentre eles a intensa terceirização da atividade, que culminava na informalidade acirrada dos contratos, na falta de segurança no translado dos trabalhadores, na falta de condições dignas de alimentação e de moradia, no papel do Estado na geração de alternativas para o número de trabalhadores desempregados, na fiscalização das contratações através do executivo, etc. No site da SGPR, podemos observar que tais problemas foram objetos específicos de atuação da Secretaria, comprometendo o patronato à contratação direta de trabalhadores via órgãos do Ministério do Trabalho e Emprego - MTE, ao oferecimento de transportes seguros, oferecimento de equipamentos de proteção, etc. A SGPR estima em mais de 12 mil o número de trabalhadores atendidos pelas políticas aprovadas a partir do Compromisso Nacional ${ }^{8}$. Outras medidas também dispostas pelo Compromisso foram os programas de capacitação, incentivados pelo governo, visando qualificar os trabalhadores. E aqui cabe destacar singularidades do projeto da FERAESP em relação ao projeto cutista mais geral, conforme visualizado nos debates sobre o Compromisso Nacional: enquanto a visão de formação anunciada pelo governo federal tem, como norte, a qualificação dos trabalhadores para o exercício de outras funções na dinâmica produtiva nacional, a visão do dirigente da FERAESP comporta também outros significados:

8Trabalhadores atendidos pela contratação direta no período de 2010 a 2011, segundo a SGPR: Minas Gerais (Salinas, Teófilo Otoni, Almenara): aproximadamente 12 mil trabalhadores intermediados; Piauí (Barras, Teresina e Floriano): aproximadamente um mil trabalhadores intermediados; Maranhão (Açailândia, Codó, Bacabal e Pedreiras): aproximadamente 1,5 mil trabalhadores intermediados; Mato Grosso (Nova Olímpia, São José do Rio Claro, Lambari d'Oeste, Mirassol d'Oeste, Barra do Bugres e Campo Novo do Parecis): aproximadamente 6 mil trabalhadores intermediados. Fonte: Ministério do Trabalho e Emprego/MTE - em 09/08/12.

Brasiliana - Journal for Brazilian Studies. Vol. 2, n.2 (Nov 2013). ISSN 2245-4373. 
"É uma qualificação do trabalhador, para o trabalhador, não para o capital [...] Vamos imaginar, nós vamos formar uma enorme quantidade de tratoristas pra trabalhar pra usina, que vão desempregar outros tratoristas dentro das usinas. Você reproduz o desemprego. [...] Porque o sindicalismo deveria estar usando sua energia pra qualificar trabalhadores para a cidadania, não para ser subordinado. [...] Só que para o trabalhador ser sujeito, ele precisa ser classe [...]. O Estado está organizado, se a massa trabalhadora não tiver organizada, se ela não tiver consciência, cidadania, ela não chega a condição de sujeito. Ela não promove equilíbrio, ela não promove transformação. O esforço, não me pergunte se vai estar certo ou não, o que me mantém no sindicalismo é isso: é a possibilidade de construir essa capacidade do trabalhador ser sujeito." (Milano e Pera, 2009: 7)

A capacitação, conforme vista pela FERAESP, difere da proposta do governo e da CUT em particular. Enquanto que para a CUT a extinção gradativa dos postos de trabalho pela mecanização justificaria o esforço na capacitação dos trabalhadores para outras funções e postos de trabalhos (CUT, 2000), para a FERAESP a capacitação tem forte viés de formação política e desponta, inclusive, como possibilidade da luta pela reforma agrária e para a autonomia do trabalhador (Milano e Pera, 2009: 17)9 .

Por parte dos empregadores, um dos principais personagens envolvidos na "difusão positiva" da matriz energética nacional foi a UNICA, que se projetava

9 Élio Neves aponta que a disputa pelos recursos estatais na formação para a cidadania dos trabalhadores se materializou numa escola de formação em Barrinha, cidade dormitório que hoje conhece elevadíssimos índices de desemprego, por conta da perda de postos de trabalho pela mecanização do corte da cana. Entrevistas recentes apontam que a entidade oferece disciplinas de "cidadania" e "ética" nos cursos de formação e requalificação profissional.

Brasiliana - Journal for Brazilian Studies. Vol. 2, n.2 (Nov 2013). ISSN 2245-4373. 
mundialmente, às vezes sob a companhia do Presidente Lula e de um corpo de diplomatas brasileiros (Teixeira, 2013). Antonio Lambertucci (2010) aponta também que a ÚNICA, por diversos momentos, interferiu na determinação de participantes e dos pontos a serem negociados, através de ameaças de se retirar dos espaços de negociação. Para a ÚNICA, os problemas trabalhistas:

"São casos pontuais [...], as exceções são transformadas em regra. Não se dá nenhum crédito aos avanços no setor [...]. Só se procuram as exceções, transformadas em reportagem. [Conflito trabalhista] não é amplo, não é generalizado. Há vários avanços de postura. A UNICA não aceita que se coloquem questões pontuais e isoladas como regras do setor. Elas não são a regra." (Para usineiros..., 2008).

A retórica patronal também esteve carregada da ideia de que os mercados é que deveriam dar conta da supressão dos conflitos, forçando "mudanças graduais e efetivas de cultura e práticas laborais no setor." (Teixeira, 2013). Outro representante da ÚNICA, quando abordado sobre o descumprimento de um termo de ajustamento de conduta TAC -, junto ao Ministério Público do Trabalho (MPT), respondeu: “Temos o compromisso de acabar com o trabalho manual até 2017. Então, não temos motivo para discutir essas medidas que só funcionarão a curto prazo." (Madureira, 2008).

Tais episódios dão os contornos do projeto empresarial para o trabalho nos canaviais brasileiros. Apoiados em marcos regulatórios complementares em relação à legislação trabalhista sobre o trabalho manual/mecanização ${ }^{10}$, empresários continuam a

10 Em 1997, por pressão de diferentes atores da sociedade civil, o Governo do Estado de São Paulo lança a Lei 10.547 que disciplina o uso de queimadas e estabelece prazos para erradicação do corte manual na cultura canavieira em todo o Estado.

Brasiliana - Journal for Brazilian Studies. Vol. 2, n.2 (Nov 2013). ISSN 2245-4373. 
enfatizar a livre negociação entre sindicatos laborais-patronais. José Pastore, intelectual interpelado nas argumentações da ÚNICA, defendeu a seguinte tese comentando o Compromisso da Cana-de-açúcar:

"Apesar de muito se enaltecerem as virtudes da livre negociação, entre nós ela é mais combatida do que apoiada. Na sua maioria, os sindicatos de empregados e de empregadores evoluíram na arte de negociar. Nas mesas de negociação, o que era um teatro passou a ser um exercício de defesa de posições com base em dados e argumentos. Concluída a negociação, as partes não sabem se o que foi acertado hoje valerá amanhã. Isso porque os poderes públicos interferem sem cerimônia no resultado dela. Procuradores, auditores fiscais e juízes, com honrosas exceções, acham que sabem mais do que as próprias partes. Esta deveria ser a hora de as autoridades se irmanarem na cruzada de tudo fazer para aperfeiçoar as condições de trabalho na difícil cultura da cana-deaçúcar, homenageando, assim, um esforço pioneiro de autocontrole das partes. Esse mecanismo poderia ajudá-las no provimento de dados para a execução de suas próprias missões de fiscalizar e julgar. Afinal, os elementos das verificações do cumprimento do acordo são públicos, em especial, para os poderes constituídos." (Pastore, 2012, grifos do autor, GST).

Os principais esforços patronais se orientam para o fortalecimento da "livre negociação", entendida como aquela que não guarda, necessariamente, relação com a legislação vigente. $\mathrm{O}$ "aperfeiçoamento" das condições de trabalho, por sua vez, aparece relacionado com a livre negociação entre os sindicatos de empregados e empregadores, 
visando reduzir a influência daqueles que "acham que sabem mais do que as próprias partes". As representações patronais, durante toda a elaboração do Compromisso Nacional, foram contrárias às normas de caráter vinculativo e obrigatório, o que acabou legitimando um protocolo de adesão facultativa.

O maior peso político do patronato no Compromisso Nacional parece estar relacionado, em parte, pela nova organização do setor sucroalcooleiro na atualidade. A matriz nacional passou recentemente por uma forte onda de investimentos estrangeiros, a partir de grandes multinacionais, petroleiras, fundos de investimentos e parceiros acionários de diversas origens. Esse novo perfil acabou por acionar também novas demandas e relações de sustentação econômica e política (Tabela 2). O patronato passa assumir posições chave dentro de órgãos vinculados com a normatização e logística da produção sucroalcooleira, a partir de empresas como a Petrobrás, como o BNDES, ou mesmo em postos estratégicos dentro de alguns ministérios. Tais características parecem influenciar as principais políticas recentes para o etanol e para o setor sucroenergético como um todo.

Parece-nos claro que se o projeto de "desenvolvimento com equidade" de setores à esquerda do governo implicava na expansão do setor sucroenergético brasileiro no seu conjunto, não o faria sem enquadrar o patronato naquilo que considerava como "humanização do trabalho". Ainda que tal debate tenha se constituído a partir da forte intervenção e influência do patronato, certamente devemos compreender tal enquadramento como expressão de disputas sobre os termos que balizariam a expansão sucroalcooleira no país a partir de então. Um exemplo é a organização por local de trabalho, pauta antiga sustentada pela FERAESP e pelo sindicalismo cutista em geral, pode ser observada num dos pontos finais do Compromisso Nacional ${ }^{11}$. No entanto, 
Teixeira, Gabriel da Silva. A Política numa Política do Trabalho Escravo: Alguns Apontamentos sobre o Compromisso Nacional da Cana de Açúcar.

como também já pontuamos, algumas limitações preliminares, como a exclusão de setores sociais, como pastorais, a Contag e ONG's, dão sinais das políticas tecidas por traz da elaboração do Compromisso Nacional.

$11 \mathrm{Na}$ cláusula $2^{\mathrm{a}}$ do acordo firmado em 2009, no subitem intitulado "Organização Sindical e Negociações Coletivas", observamos o seguinte ponto: "b) assegurar acesso aos locais de trabalho de dirigentes de sindicato, federação ou confederação da respectiva base territorial, desde que esteja previamente credenciado e seja a empresa comunicada de maneira simplificada e com antecedência, para verificar eventuais problemas e buscar soluções junto aos representantes da empresa; e c) orientar os líderes de equipe sobre a importância do respeito às atividades sindicais."

Brasiliana - Journal for Brazilian Studies. Vol. 2, n.2 (Nov 2013). ISSN 2245-4373. 
Tabela 2. Exemplos de algumas personalidades políticas contratadas pelas empresas sucroenergética nacionais nos anos recentes. FONTE: Teixeira (2013).

\begin{tabular}{|c|c|c|c|c|}
\hline Nomes/Grupo & $\begin{array}{c}\text { Curso de } \\
\text { Graduação/Inst; } \\
\text { Pós/Inst. } \\
\end{array}$ & $\begin{array}{l}\text { Atuação na esfera } \\
\text { governamental }\end{array}$ & Experiência em Finanças & Trajetória profissional em outras áreas \\
\hline $\begin{array}{l}\text { Armínio Fraga } \\
\text { Neto/Cosan }\end{array}$ & $\begin{array}{l}\text { Ph.D em Economia pela } \\
\text { Universidade de } \\
\text { Princeton e B.A. e M.A. } \\
\text { em Economia pela } \\
\text { Universidade Católica } \\
\text { do Rio de Janeiro }\end{array}$ & $\begin{array}{l}\text { Ex-presidente do Banco } \\
\text { Central do Brasil (mar. de } \\
1999 \text { a dez. de 2002) }\end{array}$ & $\begin{array}{l}\text { Atual presidente do } \\
\text { Conselho de } \\
\text { Administração da } \\
\text { BMF\&Bovespa. Sócio } \\
\text { fundador da Gávea } \\
\text { Investimentos (fundo } \\
\text { que aplica recursos no } \\
\text { setor). Anteriormente foi } \\
\text { diretor Gerente da Soros } \\
\text { Fund Manegement em } \\
\text { Nova York, Diretor de } \\
\text { Assuntos Internacionais } \\
\text { do Banco Central do } \\
\text { Brasil, vice presidente da } \\
\text { Salomon Brothers, em } \\
\text { Nova York e economista } \\
\text { chefe e gerente de } \\
\text { operações do Banco } \\
\text { Garantia. }\end{array}$ & $\begin{array}{l}\text { Foi professor do curso de mestrado da } \\
\text { Universidade Católica do Rio de } \\
\text { Janeiro, da Escola de Economia da FGV, } \\
\text { da School of International Affairs da } \\
\text { Universidade de Columbia e da } \\
\text { Wharton School. Acionista da Cosan } \\
\text { Limited, representado pelo Conselheiro } \\
\text { Hélio Franca Filho. }\end{array}$ \\
\hline $\begin{array}{c}\text { Eduardo Pereira de } \\
\text { Carvalho/ } \\
\text { ETHbioenergia }\end{array}$ & $\begin{array}{c}\text { Formado pela } \\
\text { Faculdade de Ciências } \\
\text { Econômicas e } \\
\text { Administrativas da } \\
\text { Universidade de São } \\
\text { Paulo. }\end{array}$ & $\begin{array}{l}\text { Ex-diretor da Cia. Vale do } \\
\text { Rio Doce (1977-79). Ex- } \\
\text { secretário da Agricultura do } \\
\text { Estado de São Paulo, } \\
\text { Secretário Geral no } \\
\text { Ministério da Fazenda de } \\
\text { 1980-81 e substituto do }\end{array}$ & $\begin{array}{l}\text { Foi Coordenador da } \\
\text { Assessoria Econômica do } \\
\text { Ministério da Fazenda de } \\
\text { 1970-74. Diretor } \\
\text { Financeiro da SAFRON } \\
\text { TEJIN S/A - Industria } \\
\text { Brasileira de Fibras. }\end{array}$ & $\begin{array}{l}\text { Professor Catedrático da mesma Escola } \\
\text { que se graduou. Foi Presidente da } \\
\text { UNICA entre } 2000 \text { e 2007. É o atual } \\
\text { Presidente da PREVER - Previdência } \\
\text { Privada (Bancos Bamerindus e } \\
\text { Unibanco). Conselheiro da } \\
\text { ETHbioenergia até } 2010 .\end{array}$ \\
\hline
\end{tabular}




\begin{tabular}{|c|c|c|c|c|}
\hline & & $\begin{array}{l}\text { Ministro da Fazenda. Foi } \\
\text { Presidente do BANESPA }\end{array}$ & & \\
\hline $\begin{array}{l}\text { Henri Philippe } \\
\text { Reichtsul/ Brenco }\end{array}$ & $\begin{array}{c}\text { Graduou-se em } \\
\text { Economia e } \\
\text { Administração de } \\
\text { Empresas na USP. } \\
\text { Cursou pós-graduação } \\
\text { em Hertford College, na } \\
\text { Oxford University }\end{array}$ & $\begin{array}{l}\text { Ex-Presidente da Petrobrás, } \\
\text { do IPEA (Instituto de } \\
\text { Pesquisa Econômica } \\
\text { Aplicada). Trabalhou no } \\
\text { Ministério do Planejamento } \\
\text { com João Sayad. }\end{array}$ & $\begin{array}{c}\text { Ex-Diretor Vice- } \\
\text { Presidente Executivo do } \\
\text { Inter American Express } \\
\text { Bank S/A. Ao lado de } \\
\text { Sayad e Francisco Vidal } \\
\text { Luna fundou o Banco } \\
\text { SRL, depois comprado } \\
\text { pelo grupo American } \\
\text { Express. }\end{array}$ & $\begin{array}{l}\text { Conselheiro e CEO da Brenco e sócio } \\
\text { fundador. Atuou também como } \\
\text { membro do Conselho de Administração } \\
\text { da Eletrobrás, do BNDES, da Caixa } \\
\text { Econômica Federal, da Globopar. É } \\
\text { membro do Conselho de Administração } \\
\text { da Ashmore Energy International, da } \\
\text { Repsol-YPF, da PSA-Pegeout Citroen, } \\
\text { do Conselho Consultivo da Lhoist do } \\
\text { Brasil. }\end{array}$ \\
\hline $\begin{array}{c}\text { Humberto } \\
\text { Casagrande/ Terra } \\
\text { Viva }\end{array}$ & $\begin{array}{c}\text { Engenheiro de } \\
\text { Produção pela UFSCar. } \\
\text { Mestre em } \\
\text { Administração de } \\
\text { Empresas pela PUC-SP. }\end{array}$ & $\begin{array}{l}\text { Ex-Secretário adjunto da } \\
\text { SEST/SEPLAN na gestão do } \\
\text { Ministro João Sayad }\end{array}$ & $\begin{array}{l}\text { Ex-Diretor dos Bancos } \\
\text { Citibank, Sudameris, } \\
\text { Credibanco. }\end{array}$ & $\begin{array}{l}\text { Ex-Presidente da APIMEC nacional } \\
(2001-4) \text {. Ex-conselheiro da Bovespa. } \\
\text { Professor de mercado de capitais com } \\
\text { diversos livros publicados. }\end{array}$ \\
\hline $\begin{array}{l}\text { Mailson Ferreira da } \\
\text { Nóbrega/ Cosan }\end{array}$ & & $\begin{array}{l}\text { Ministro da Fazenda entre } \\
\text { 1988-90. Carreira no Banco } \\
\text { do Brasil e no setor público. } \\
\text { Consultor técnico e chefe do } \\
\text { departamento de análises de } \\
\text { projetos do Banco do Brasil; } \\
\text { coordenador chefe de } \\
\text { Assuntos Econômicos do } \\
\text { Ministério da Indústria e } \\
\text { Comércio e Secretário Geral } \\
\text { do Ministério da Fazenda. }\end{array}$ & $\begin{array}{l}\text { Atuou como Diretor } \\
\text { Presidente do Banco } \\
\text { Europeu Brasileiro } \\
\text { (Eurobraz) em Londres. }\end{array}$ & $\begin{array}{l}\text { Conselheiro da Cosan e Cosan Limited. } \\
\text { desde 2007. Foi membro do Conselho } \\
\text { de Administração das Seguintes Cias: } \\
\text { Abyara Planejamento Imobiliário, CSU } \\
\text { Carsystem S/A., Grendene S/A., } \\
\text { Portobello S/A., Rodobens Negócios } \\
\text { Imobiliários S/A., TIM Participações } \\
\text { S/A. e Veracel Celulose S/A. }\end{array}$ \\
\hline $\begin{array}{c}\text { Marcus Vinicius } \\
\text { Pratini de Moraes/ } \\
\text { Cosan } \\
\end{array}$ & $\begin{array}{c}\text { Graduado em } \\
\text { Economia pela } \\
\text { Faculdade de Ciências } \\
\end{array}$ & $\begin{array}{c}\text { Ministro Interino do } \\
\text { Planejamento e } \\
\text { Coordenação Geral (1968- } \\
\end{array}$ & $\begin{array}{l}\text { Membro do Conselho da } \\
\text { FIC - International } \\
\text { Finance Corporation }\end{array}$ & $\begin{array}{l}\text { Membro do Conselho de } \\
\text { Administração da Cosan desde } 2005 . \\
\text { Foi fundador da FUNCEX (1976-85), }\end{array}$ \\
\hline
\end{tabular}




\begin{tabular}{|c|c|c|c|c|}
\hline & $\begin{array}{c}\text { Econômicas da } \\
\text { Universidade do Rio } \\
\text { Grande do Sul (1963) e } \\
\text { pós-graduado em } \\
\text { Administração Pública } \\
\text { pela Deutsche Stiftung } \\
\text { fur Entwicklungslander } \\
\text { - Berlim (1965) e } \\
\text { Administração de } \\
\text { Empresas pela } \\
\text { Pittsburgh University \& } \\
\text { Carnegie Tech - } \\
\text { Carnegie institute of } \\
\text { Technology (1966). }\end{array}$ & $\begin{array}{l}\text { 69), Ministro da Industria e } \\
\text { do Comércio (1970-74), } \\
\text { Ministro da Agricultura, } \\
\text { Pecuária e do } \\
\text { Abastecimento (1999-2002), } \\
\text { além de um mandato de } \\
\text { Deputado Federal pelo } \\
\text { Estado do Rio Grande do } \\
\text { Sul (1982-86). }\end{array}$ & & $\begin{array}{l}\text { Presidente do Conselho Consultivo do } \\
\text { Center of Brazilian Studies (School of } \\
\text { Advanced Studies/John Hopkins } \\
\text { University, entre 1977-81). Presidente } \\
\text { da Associação do Comércio Exterior do } \\
\text { Brasil - AEB (1998-99), Membro do } \\
\text { Conselho de Supervisão do Banco } \\
\text { ABN-AMRO - Amsterdã (2003)- } \\
\text { Membro do Conselho Consultivo da } \\
\text { BM\&F (2003), Presidente do Conselho } \\
\text { da ABIEC (2003), Membro do Conselho } \\
\text { Empresarial Brasil-China (2004), } \\
\text { Presidente do Conselho Empresarial } \\
\text { Brasil-Rússia (2004), Membro do } \\
\text { Conselho Nacional de } \\
\text { Desenvolvimento Industrial (2005-07) e } \\
\text { Vice-Presidente do Serviço de } \\
\text { Informação da Carne-SIC (2005). }\end{array}$ \\
\hline $\begin{array}{c}\text { Pedro Pulen } \\
\text { Parente/ BUNGE }\end{array}$ & $\begin{array}{c}\text { Graduado Em } \\
\text { Engenharia Elétrica pela } \\
\text { Universidade de } \\
\text { Brasília }\end{array}$ & $\begin{array}{l}\text { Funcionário de carreira do } \\
\text { Banco Central, onde se } \\
\text { aposentou em 2010. Ex- } \\
\text { Ministro (1999-2002), } \\
\text { coordenador da equipe de } \\
\text { transição do Governo FHC } \\
\text { para o Governo Lula. }\end{array}$ & $\begin{array}{l}\text { Foi Consultor do Fundo } \\
\text { Monetário Internacional } \\
\text { e de instituições públicas } \\
\text { no país, incluindo } \\
\text { Secretarias de Estado e a } \\
\text { Assembleia Nacional } \\
\text { Constituinte de 1988, } \\
\text { tendo atuado em } \\
\text { diversos cargos na área } \\
\text { econômica do Governo. }\end{array}$ & $\begin{array}{l}\text { Atuou também como Presidente da } \\
\text { Câmara de Gestão da Crise de Energia } \\
\text { de 2001-02. No período de } 2003 \text { até } 2009 \\
\text { foi Vice-Presidente Executivo do Grupo } \\
\text { RBS. É Presidente e CEO da BUNGE } \\
\text { Brasil desde janeiro de } 2010 . \\
\text { Atualmente é membro dos conselhos da } \\
\text { AMCHAM Brasil, RBS, FNQ e da } \\
\text { BM\&FBOVESPA. }\end{array}$ \\
\hline $\begin{array}{c}\text { Roberto Rodrigues/ } \\
\text { AGROERG }\end{array}$ & $\begin{array}{l}\text { Formou-se em } \\
\text { Engenharia } \\
\text { Agronômica com }\end{array}$ & $\begin{array}{l}\text { Ministro da Agricultura } \\
(2003-06) .\end{array}$ & $\begin{array}{l}\text { Ex-Conselheiro da } \\
\text { BM\&FBOVESPA. }\end{array}$ & $\begin{array}{l}\text { Produtor e fornecedor de cana-de- } \\
\text { açúcar no Estado de São Paulo. } \\
\text { Professor Emérito do Depto. De }\end{array}$ \\
\hline
\end{tabular}




\begin{tabular}{|c|c|c|c|c|}
\hline & $\begin{array}{l}\text { aperfeiçoamento em } \\
\text { administração rural } \\
\text { pela Escola Superior de } \\
\text { Agricultura da USP em } \\
1965 .\end{array}$ & & & $\begin{array}{l}\text { Economia Rural da Unesp de } \\
\text { Jaboticabal. Professor da FGV-SP. É } \\
\text { membro dos Conselhos da Fundação de } \\
\text { Estudos Agrários “Luiz de Queiroz” } \\
\text { (FEALQ), da Administração da Escola } \\
\text { de Administração de Empresas de São } \\
\text { Paulo (FGV) e da Fundação Bunge. Ex- } \\
\text { Presidente da Associação Brasileira de } \\
\text { Agribusiness (ABAG) e membro do } \\
\text { Comitê Empresarial de Comércio } \\
\text { Exterior do Itamaraty, além de } \\
\text { participar de vários conselhos ligados } \\
\text { ao agronegócio no Brasil como o } \\
\text { Conselho Nacional do Agronegócio do } \\
\text { Ministério da Agricultura. Ex- } \\
\text { Presidente da Organização } \\
\text { Internacional de Cooperativas } \\
\text { Agrícolas. }\end{array}$ \\
\hline $\begin{array}{l}\text { Segio Thompson } \\
\text { Flores/ Infinity Bio } \\
\text { Eenergy }\end{array}$ & $\begin{array}{l}\text { Bacharel e mestre em } \\
\text { Relações Internacionais } \\
\text { pelo instituto Rio } \\
\text { Branco. }\end{array}$ & $\begin{array}{l}\text { Foi diplomata no Serviço } \\
\text { Exterior Brasileiro, em um } \\
\text { posto Senior no Ministério } \\
\text { da Fazenda. Foi Diretor do } \\
\text { Finep, com atividades em } \\
\text { gestão de fundos financeiros } \\
\text { (private equity) e } \\
\text { financiamento de projetos. }\end{array}$ & $\begin{array}{l}\text { Entre 1996-2006 dirigiu a } \\
\text { Worldinvest, assessoria } \\
\text { financeira e de } \\
\text { desenvolvimento de } \\
\text { negócios no Brasil, da } \\
\text { qual foi o principal sócio } \\
\text { e fundador. }\end{array}$ & $\begin{array}{l}\text { Membro do Conselho de } \\
\text { Administração e diretor presidente da } \\
\text { Infinity Bio Energy desde março de } \\
2006 .\end{array}$ \\
\hline
\end{tabular}




\section{A "Qualidade" da Participação Social: o que o Compromisso Nacional Pode Nos Dizer?}

A solenidade de entrega dos selos às empresas certificadas, em 2012, foi um momento impar para perceber a forma como a arena era percebida pelas distintas representações. Antônio Lucas, representante da CONTAG, por ocasião da solenidade afirmou: "queremos retomar aquela pauta inicial que não foi negociada" (Teixeira, 2013). Tal afirmação se soma às criticas tecidas por Élio Neves sobre a determinação dos participantes da Mesa.

Outro aspecto diz respeito à marginalização do Judiciário, que acabou perdendo o protagonismo na atribuição de conformidade trabalhista às empresas nacionais. Para o Procurador do MPT de Araraquara, Rafael Gomes,

"mesmo as piores usinas do país flagradas cometendo ilícitos graves (inclusive trabalho escravo) eram todas signatárias desse Compromisso.[...]. Parece agora claro, também, que o principal interesse em torno do acordo estava na concessão de um selo governamental às usinas, destinado a facilitar as exportações." (Acordo e Certificações.., 2013)

Para o MPT o conflito dava-se porque os critérios da certificação para definição de "empresas responsáveis" desconsideravam os diversos litígios e condenações feitas pelo 
judiciário. Assim, na prática, a certificação das empresas acabava por contornar a legislação vigente ${ }^{12 .}$

No que diz respeito à fiscalização dos pontos pactuados, observou-se desde fraudes até a coação de trabalhadores durante entrevistas colhidas pelos auditores. Quando analisados os currículos dos auditores ou responsáveis pela auditagem nas empresas, ficam explícitos os trânsitos de profissionais entre as empresas de auditagem e as usinas a serem auditadas (Quadro 1).

Quadro 1 - Trânsito de profissionais entre grupos empresariais sucroalcooleiros e empresas auditoras. Fonte: (Teixeira, 2013) ${ }^{13}$.

\begin{tabular}{|l|l|}
\hline $\begin{array}{l}\text { Empresa } \\
\text { Auditoria }\end{array}$ & Profissionais que transitaram \\
\hline KPMG & $\begin{array}{l}\text { Maria foi consultora da KPMG entre 2007 e 2008, sendo no mesmo ano contratada } \\
\text { como coordenadora do setor fiscal da ETH Bioenergia (Odebrecht). } \\
\text { Jorge trabalhou na Usina Cerradinho Açúcar e Álcool S/A. entre 2004 e 2006. Entre } \\
\text { 2007 e 2009 trabalha na Nardini Agroindustrial Açúcar e Álcool. Entre 2009 e 2011 foi } \\
\text { auditor externo da KPMG. } \\
\text { Marcelo foi auditor da KPMG de 1996 a 2003, tornando-se Gerente Corporativo de } \\
\text { Custos e Orçamento no Grupo Farias entre 2006 e 2007. Foi também Gerente } \\
\text { Administrativo e Financeiro do Grupo Equipav entre 2007 e 2009. } \\
\text { Alexandre foi Gerente de auditoria da KPMG entre 2011 e 2012, sendo } \\
\text { anteriormente Supervisor Contábil e Fiscal na Paraíso Bioenergia (2010-11) e } \\
\text { Controllet na Gaia Energia e Participaçôes (Bertin Energia), entre 2006 e 2010. }\end{array}$ \\
\hline Delloitt Touche & $\begin{array}{l}\text { Oatual Auditor Assistente, Rubens, foi estagiário da Clealco em 2011. } \\
\text { Gerente de Auditoria da mesma empresa entre 2008 e 2010. Entre 2010 e 2011 } \\
\text { tornou-se gerente da KPMG no atendimento a clientes no ramo de açúcar, álcool e } \\
\text { agronegócio. A partir de 2011 até os dias atuais é Analista sênior do Grupo São } \\
\text { Martinho. }\end{array}$ \\
\hline
\end{tabular}

12 Goiás assistiu a um caso onde um juiz deu causa ganha à empresa, acusada pelo não cumprimento da legislação trabalhista. Em seu argumento, as alegações "não cabiam”, posto que a empresa "já era atestada" como "empresa exemplar" pelo Compromisso Nacional. O juiz "sensibilizou-se com a alegação de que a empresa já havia sido submetida à auditoria, que não localizou quaisquer problemas trabalhistas, e deferiu a liminar pedida pela empresa, suspendendo a decisão anterior" (MINISTÉRIO PÚBLICO DE ARARAQUARA, 2012, p. 28).

13 Os nomes foram trocados a fim de preservar a identidade dos funcionários.

Brasiliana - Journal for Brazilian Studies. Vol. 2, n.2 (Nov 2013). ISSN 2245-4373. 
Dagnino e Tatagiba (2010) entendem que é mais proveitoso pensar em termos da coexistência de matrizes culturais distintas no imaginário e no repertório social do que em sua brusca substituição a partir de práticas políticas mais democráticas. As autoras tencionam no sentido de pensar que os espaços participativos não estão imunes das ambivalências e contradições presentes na sociedade, como a forte tutela dos processos de auditagem por parte das empresas. Em outro texto, este raciocínio aparece melhor desenvolvido:

\footnotetext{
"De um lado, os projetos - aqueles não conservadores - são formulados precisamente para confrontar e modificar elementos presentes nessas histórias e contextos. Por outro lado, esses projetos e as práticas por eles orientadas, não estão, evidentemente, imunes a esses mesmos traços, característicos das matrizes culturais vigentes na América Latina" (Dagnino, Olvera e Panfichi, 2006: 44)
}

A compreensão de que espaços participativos representam uma reivindicação de diversos segmentos sociais, além de uma tentativa de se contrapor às práticas políticas tradicionais, baseadas no mandonismo, no favorecimento e no clientelismo, não impede o reconhecimento da persistência de tais repertórios no seu interior. Nossa atenção deveria recair, de acordo com esta chave, para a tensão entre as eventuais práticas políticas de caráter privatista e as novas práticas mais públicas e democráticas que se pretendem inaugurar. A contribuição de pensar o acordo da cana-de-açúcar em termos dessa "tensão" (Dagnino e Tatagiba, 2010) entre culturas políticas mais privatistas e outras mais democráticas permite-nos compreender a manutenção de relações baseadas 
no favorecimento privado, mesmo numa arena que se propõe mais democrática e transparente. Vistas como clientes pelos auditores, as usinas eram percebidas, inclusive, como possibilidade futura de emprego. (Teixeira, 2013), o que pareceu influenciar a qualidade da fiscalização.

Outro importante conceito que auxilia na compreensão do Compromisso Nacional é a noção de "confluência perversa" (Dagnino, 2004). Para a autora, a "perversidade" residiria no fato de que apontando em direções opostas e até mesmo antagônicas, distintos projetos políticos acabam por se utilizar de um discurso e palavras em comum. Para os setores de esquerda do governo a "humanização do trabalho" era vista como possibilidade de enquadrar o patronato no cumprimento de bandeiras sindicais e trabalhistas até então fracamente cumpridas (Henrique, 2013). Para o patronato, por outro lado, significava a conciliação não conflitiva dos atores que compõe a sociedade do agronegócio canavieiro em torno da expansão da atividade. Significava também a criação de regulamentos não vinculativos que atestassem a conformidade da produção de etanol, mesmo diante de uma diversidade de conflitos e litígios judiciais. O "aperfeiçoamento" das condições de trabalho concretiza também, acredito, a iniciativa patronal de regulamentação pontual e específica das relações trabalhistas, enquanto que para os trabalhadores o "aperfeiçoamento" das condições de trabalho parece apontar na direção da conquista de ganhos imediatos concretos, muitos já reivindicados há décadas, mas poucas vezes cumpridos.

Nas pesquisas de campo realizadas, muitas lideranças sindicais entrevistadas apresentavam pouco conhecimento sobre o acordo ou repudiavam-no em algum grau. No inquérito elaborado pelo MPT, das 7 usinas avaliadas, todas portavam irregularidades graves no cumprimento dos pontos pactuados e em 6 delas o processo 
de auditagem não tinha sido objeto de conhecimento dos sindicatos da região. $\mathrm{O}$ recurso aos casos serve para mostrar que mesmo deliberado, os desafios para a implementação dos pontos pactuados foram grandes e dependem, de certo modo, da capacidade dos grupos subalternos agirem de forma coesa e bem organizada. Para Dagnino e Tatagiba (2010) buscar a interferência no jogo político através da representação pode significar a utilização de energia e de quadros políticos significativos na atuação institucional, em detrimento de maior proximidade com as bases e da redefinição das identidades do próprio movimento social. Miguel (2010), também sugere que para que a representação figure como exercício de poder, deve haver um fluxo "simétrico" entre as bases e seus representantes. Dito de outra forma, um dos desafios da representação institucional de atores políticos subalternos está em fazer da representação um mecanismo capaz de intensificar e garantir um diálogo mais efetivo entre representantes e representados. Se feito de outra forma, a representação poderia ser vista como "delegação", significando, em última instância, um afastamento das bases sociais de apoio e a perda do poder de mobilização, que é, em ultima instância, poder político. A relação base-representante, nos termos acima descritos, poderiam nos ajudar a compreender os desafios a serem enfrentados pelo movimento sindical brasileiro?

Outro autor que também traz provocações interessantes para se pensar os desafios da participação institucional é Claus Offe (1989). Empresários não veriam comprometidas suas finalidades principais (eficiência econômica) caso não cumpram os pontos acordados num pacto tripartite qualquer. Para o par capital a inclusão em espaços tripartites não implica, no mesmo grau que para os trabalhadores, na diminuição seu poder de barganha, nem garante, por si só, a adesão do conjunto das empresas às metas tidas como desejáveis. Isso porque os interesses dos atores vinculados à acumulação capitalista já estão parcialmente dados de antemão, a saber, o 
lucro e a manutenção de condições propícias à continuidade da acumulação. Uma entidade representativa de empresas individuais não gera um poder que estas já não tenham e nem formulam objetivos que não derivem diretamente daqueles que já são definidos - e conscientemente perseguidos - ao nível das empresas individuais participantes (Offe, 1989: 258). Por outro lado, para os trabalhadores, a participação institucional só consiste em avanço caso estes estejam em condições de atuar coletivamente, impondo ao patronato o cumprimento dos pontos acordados.

Cabe destacar que, atualmente, o conjunto dos acordos entre trabalhadores e patrões parece ter perdido a validade. Antônio Lucas, representante da CONTAG afirma que ao final do processo, teria sido "enganado" e "usados" para que os usineiros pudessem ganhar mais dinheiro (Acordo e Certificações, 2013).

Os eventos brevemente apresentados revelam a diversidade de projetos políticos para a atividade canavieira. Empresários, sindicalistas e outros representantes políticos se lançam na tarefa de disputar a forma e o conteúdo das políticas públicas destinadas para o setor, em especial para políticas sociais e trabalhistas, no caso através do Compromisso Nacional. A despeito do que afirmam os principais idealizadores, a política participativa da cana-de-açúcar tem pouco de cooperação, como demonstram a continuidade dos embates e conflitos, da exclusão de participantes, da disputa pelo conteúdo, de fraudes nas fiscalizações e nas tentativas sindicais de disputar o conteúdo das capacitações de trabalhadores.

Ao contrário dos discursos institucionais e governamentais, antes de cessar com os embates entre empresas, trabalhadores rurais e sindicatos, a intensa mecanização da lavoura canavieira e a expansão recente do complexo agroindustrial sucroenergético parece tem ampliado o abismo social e político entre empresas e trabalhadores. A 
mecanização da cana também não se dá sem conflitos. As empresas, cada vez mais ricas e reestruturadas, ainda lançam mão de práticas político-sociais privatistas, clientelistas e baseadas no favorecimento individual. No caso do Compromisso Nacional, a participação ainda contou, fortemente, com práticas pouco públicas e democráticas.

\section{Referências Bibliográficas.}

Acordo e Certificações, sobre o trabalho na cana perdem a validade. Disponível em: http://reporterbrasil.org.br/2013/07/acordo-e-certificacoes-sobre-trabalho-na-canaperdem-validade/. Acesso em agosto, 2013.

BNDES. O perfil do apoio do BNDES ao setor sucroalcooleiro. Rio de Janeiro, n. 28, set., pp. 3-36, 2008. Disponível em: http://www.bndes.gov.br/. Acesso em: 13 abr. 2011.

Corrêa, E. A organização sindical dos trabalhadores rurais: os canavieiros de Cosmópolis/SP. Dissertação de Mestrado (Ciência Política), Unicamp. Campinas, SP. 2012.

CUT. Projeto CUT/CONTAG. Plataforma para o desenvolvimento e sindicalismo rural no Brasil, 2000.

Dagnino, Evelina. "Confluência perversa, deslocamentos de sentido, crise discursiva". Em: Grimson (ed.) La cultura en la crisis latino-americana. Clacso, Buenos Aires, 2004.

Ferrante, V. A Chama verde dos Canaviais: uma história de luta dos boias-frias. Araraquara, 1992. Tese (Livre Docência) - Faculdade de Filosofia Ciências e Letras, Universidade do Estado de São Paulo (UNESP).

Gramsci, Antônio. Maquiavel, a política e o Estado Moderno. 2ª edição. Rio de janeiro: Civilização Brasileira, 1976. 
Henrique, A. "Um olhar dos trabalhadores: um balanço positivo, uma disputa cotidiana e muitos desafios pela frente". Em: SADER (org.). 10 anos de governos pós-neoliberais no Brasil: Lula e Dilma. São Paulo: Boitempo; Rio de Janeiro: Flasco Brasil, 2013.

Lambertucci, A. Mesa Nacional de Diálogo para Aperfeiçoar as Condições de Trabalho na Cana de Açúcar: um espaço de participação. Trabalho de Especialização em Formação de Conselheiros Nacionais. Universidade Federal de Minas Gerais. Brasília, 2010.

Madureira, Roberto. "Usinas Aceitam Parar Corte de Cana se Calor Atingir 37C". In: Folha de São Paulo. 16 set. 2008. Disponível em: http://www1.folha.uol.com.br/fsp/dinheiro /fi1609200841.htm. Acesso em out. 2012.

Medeiros, L. A História dos Movimentos Sociais no Campo. São Paulo: Fase, 1989.

Miguel, L. A representação democrática: autonomia e interesse ou identidade e advocacy. 2010. (mimeo).

Milano, Mariana; PERA, Jéssica. "Entrevista com Élio Neves". In: Revista Reed, v.2, n. 1, 2009.

Ministério Público do Trabalho de Araraquara. Ação Civil Pública com Pedido de Antecipação de Tutela. Usina Ipiranga, 2012.

Moraes, M. A., Barros, G. "A Desregulamentação do Setor Sucroalcooleiro". In: Revista de Economia Política, vol. 22, no 2 (86), abril-junho/2002.

Offe, Claus. "Atribuição de status público a grupos de interesse". In: Offe Capitalismo Desorganizado: Transformações contemporâneas do trabalho e da política. 1 ed. São Paulo: Editora Brasiliense, 1989.

"Para Usineiros, Problemas São Isolados" (sem autor). In: Folha de São Paulo (sucursal Rio de Janeiro), Rio de Janeiro, 27 ago., 2008. Disponível em http://www1.folha.uol.com.br/fsp/dinheiro/fi2708200823.htm. Acesso em outubro, 2012. 
"Presidente antecipa acordo com usineiros" (sem autor). In: Valor Econômico. 16 jun., 2009. Disponível em: www.jornaldacana.com.br/Jornal-Cana/30711+Presidente-antecipaacordo-com-usineiros. Acesso novembro, 2012.

Rodrigues, Lino. "Compromisso para gringo ver: Denúncias trabalhistas atingem um terço das usinas de cana com selo de empresa responsável". In: O Globo, 21 jul., 2012. Disponível em: http://oglobo.globo.com/economia/compromisso-para-gringo-ver5549753. Acesso em novembro, 2012.

Sader, E. (Org.) Gramsci: Sobre poder, política e partido. 2ª Edição. São Paulo: Editora Brasiliense, 1992.

Secretaria Especial do Conselho de Desenvolvimento Economico e Social. Relatório de Atividades do Conselho de Desenvolvimento Econômico e Social em 2007. 2007. Disponível em www.cdes.gov.br/conteudo/888/relatorios-anuais-de-atividades-html. Acesso em 29 de jan. de 2013.

Secretaria Especial do Conselho de Desenvolvimento Economico e Social. Relatório de Atividades do Conselho de Desenvolvimento Econômico e Social em 2008. 2008. Disponível em www.cdes.gov.br/conteudo/888/relatorios-anuais-de-atividades-.html. Acesso em 29 de jan. de 2013.

Teixeira, G da S. Trabalho, tripartismo e processos sociais: Contribuições sobre o Compromisso Nacional da Cana de Açúcar. Dissertação de Mestrado. Programa de Pós Graduação em Desenvolvimento, Agricultura e Sociedade. CPDA/UFRRJ. 2013.

Trabalhadores Pediam Alimentação, mas Levaram só Marmita Térmica (sem autor). Em: O Globo. 26 jun., 2009. 